\title{
Low Visceral Fat Content Is a Negative Predictive Marker for Bevacizumab in Metastatic Colorectal Cancer
}

\author{
YUJI MIYAMOTO ${ }^{1}$, EIJI OKI ${ }^{2}$, YASUNORI EMI ${ }^{3}$, SHOJI TOKUNAGA ${ }^{4}$, MOTOTSUGU SHIMOKAWA $^{5}$, \\ YUTAKA OGATA $^{6}$, YOSHITO AKAGI ${ }^{7}$, YASUO SAKAMOTO ${ }^{1}$, TAKAHO TANAKA $^{8}$, \\ HIROSHI SAEKI $^{2}$, YOSHIHIKO MAEHARA ${ }^{2}$ and HIDEO BABA ${ }^{1}$ \\ ${ }^{1}$ Department of Gastroenterological Surgery, \\ Graduate School of Medical Sciences, Kumamoto University, Kumamoto, Japan; \\ ${ }^{2}$ Department of Surgery and Science, Graduate School of Medical Sciences, Kyushu University, Fukuoka, Japan; \\ ${ }^{3}$ Department of Surgery, Saiseikai Fukuoka General Hospital, Fukuoka, Japan; \\ ${ }^{4}$ Medical Information Center, Kyushu University Hospital, Fukuoka, Japan; \\ ${ }^{5}$ Department of Cancer Information Research, \\ National Hospital Organization Kyushu Cancer Center, Fukuoka, Japan; \\ ${ }^{6}$ Department of Surgery, Kurume University Medical Center, Kurume, Japan; \\ ${ }^{7}$ Department of Surgery, Kurume University School of Medicine, Kurume, Japan; \\ ${ }^{8}$ Department of Surgery, Social Insurance Tagawa Hospital, Tagawa, Japan
}

\begin{abstract}
Aim: This study aimed to clarify the predictive impact of visceral fat on response to bevacizumab in patients with metastatic colorectal cancer $(m C R C)$. Patients and Methods: Pretreatment computed tomography was used to measure visceral fat area (VFA) and patients with $m C R C$ receiving first-line chemotherapy with/without bevacizumab were divided by median VFA value into two groups: high VFA and low VFA. Results: In the bevacizumab-treated group, patients with low VFA had significantly shorter overall survival (OS) than patients with high VFA in univariate (median=21.1 vs. 38.9 months; hazard ratio=1.70, 95\% confidence interval $=1.06-2.70, p=0.03$ ) and multivariate analysis (hazard ratio $=1.85,95 \%$ confidence interval $=1.15-3.03, p=0.01$ ). No significant differences were seen in OS between groups treated with chemotherapy alone. The VFA had a marginally significant modifying effect on the relationship between bevacizumab and OS (p for interaction=0.07). Conclusion: Our findings provide the first evidence that a low VFA might be a negative predictive marker for response to bevacizumab in patients with $m C R C$.
\end{abstract}

Correspondence to: Dr. Hideo Baba, Department of Gastroenterological Surgery, Graduate School of Medical Sciences, Kumamoto University, 1-1-1 Honjo, Kumamoto 860-8556, Japan. Tel: +81963735212, Fax: +81963714378, e-mail: hdobaba@kumamotou.ac.jp

Key Words: Visceral fat, bevacizumab, predictive marker, metastatic colorectal cancer, cachexia.
The monoclonal antibody bevacizumab, an anti-vascular endothelial growth factor (VEGF) targeted drug, has become standard therapy for patients with metastatic colorectal cancer (mCRC) $(1,2)$. The addition of bevacizumab to cytotoxic drugs has significantly improved survival, however, the benefits of this drug in an unselected patient population are relatively modest (3). This has encouraged us to identify predictive biomarkers for response to bevacizumab in patients with mCRC (4-7).

Several studies have demonstrated that visceral obesity might be a negative predictive factor in patients with various cancer types receiving bevacizumab-based treatment (8-10). Excess visceral adipose tissue promotes cancer development and progression through increased secretion of proinflammatory and angiogenic cytokines (11-13). More recent development in computed tomography (CT) provides accurate measurement of visceral fat area (VFA) (14). On the other hand, Steffens et al. reported that renal cell carcinoma patients with low VFA had significantly worse survival outcomes compared to those with high VFA (15). A low visceral fat content possibly represents cachexia status but may also contribute to tumor angiogenesis through systemic inflammation (16).

Accordingly, we performed the current study to investigate the association between visceral fat status and response to bevacizumab in patients with $\mathrm{mCRC}$ by a retrospective analysis of five prospective phase II trials. The aim of this study was to evaluate whether visceral fat status can be a predictive marker of response to bevacizumab-based therapy for patients with mCRC. 


\section{Patients and Methods}

Data source. This analysis was conducted on a database of patients with $\mathrm{mCRC}$ prospectively enrolled in five phase II clinical trials [KSCC0501 (17), KSCC0701 (18), KSCC0801 (19), KSCC0802 (20), and KSCC0902 (21)]. We evaluated data from patients with mCRC who received first-line treatment with standard chemotherapy or standard chemotherapy plus bevacizumab. Eligibility criteria of all clinical trials included histologically confirmed CRC and measurable metastatic disease according to Response Evaluation Criteria in Solid Tumours (RECIST) (22); no previous exposure to systemic chemotherapy for metastatic disease; age 20 to 75 years; Eastern Cooperative Oncology Group Performance Status (EOCGPS) 0 to 2; and adequate organ functions. In the KSCC0802 study, patients with liver-limited mCRC (including patients with five or more metastases or with maximum tumor diameter greater than $5 \mathrm{~cm}$ ) were enrolled to evaluate liver resectability after first-line treatment. All patients who did not undergo evaluable computed tomographic (CT) scans of the abdomen and pelvis before treatment were necessarily excluded from the analysis. Patients with bowel obstruction or ascites were also excluded because visceral fat could not be evaluated accurately in these patients.

Treatment plan. In KSCC0501, patients received the FOLFOX4 regimen of oxaliplatin $\left(85 \mathrm{mg} / \mathrm{m}^{2}\right)$ on day 1 , bolus 5 -fluorouracil (5-FU; $\left.400 \mathrm{mg} / \mathrm{m}^{2}\right)$, and leucovorin $\left(200 \mathrm{mg} / \mathrm{m}^{2}\right), 22$-hour infusion of 5 -FU $\left(600 \mathrm{mg} / \mathrm{m}^{2}\right)$ on days 1 and 2 of every 2-week cycle. In KSCC0802, patients received mFOLFOX6 plus bevacizumab regimen of oxaliplatin $\left(85 \mathrm{mg} / \mathrm{m}^{2}\right)$, bolus 5 -FU $\left(400 \mathrm{mg} / \mathrm{m}^{2}\right)$, and leucovorin $\left(200 \mathrm{mg} / \mathrm{m}^{2}\right)$ and bevacizumab $(5 \mathrm{mg} / \mathrm{kg})$ on day 1 , followed by $46-\mathrm{h}$ infusion of $5-\mathrm{FU}\left(2,400 \mathrm{mg} / \mathrm{m}^{2}\right)$ on day 1 of every 2-week cycle. In KSCC0701, patients received an alternating regimen with four cycles of mFOLFOX6 followed by four cycles of FOLFIRI $\left(150 \mathrm{mg} / \mathrm{m}^{2}\right.$ irinotecan was substituted for oxaliplatin on day 1). In KSCC0801, patients received a regimen of FIREFOX plus bevacizumab consisting of four cycles of mFOLFOX6 plus bevacizumab $(5 \mathrm{mg} / \mathrm{kg})$ followed by four cycles of FOLFIRI plus bevacizumab $(5 \mathrm{mg} / \mathrm{kg})$. In KSCC0901, patients received a XELOX plus bevacizumab regimen of oxaliplatin $\left(130 \mathrm{mg} / \mathrm{m}^{2}\right)$ and bevacizumab $(7.5 \mathrm{mg} / \mathrm{kg})$ on day 1 and capecitabine $\left(2,000 \mathrm{mg} / \mathrm{m}^{2}\right)$ on days $1-14$ of every 3 weeks with leucovorin $\left(400 \mathrm{mg} / \mathrm{m}^{2}\right)$ and continuous infusion of 5 -FU $\left(600 \mathrm{mg} / \mathrm{m}^{2}\right)$ on days 1 and 2 of every 2 -week cycle. Treatment with each chemotherapy regimen was continued until disease progression or prohibitive toxicity, with the exception of KSCC0802, in which patients who were amenable to curative resection after six cycles of mFOLFOX6 plus bevacizumab underwent liver resection. All patients provided written informed consent prior to enrolment.

Quantification of VFA, subcutaneous fat area (SFA), and waist circumference (WST). The VFA, SFA, and WST were measured retrospectively on CT scans performed before treatment at the level of the umbilicus with the patient in the supine position (Figure 1a). Briefly, we used the Volume Analyzer SYNAPSE VINCENT 3D image analysis system (FUJIFILM Medical, Tokyo, Japan) to measure pixels using a window width of -190 to $-30 \mathrm{HU}$ to delineate the subcutaneous and visceral compartments and to compute the cross-sectional area of each in $\mathrm{cm}^{2}$. All measurements and calculations were performed twice by a trained examiner (Y.M.) who was blinded to the treatment outcomes at the time of quantification. Comparisons of fat area for intra-observer agreement yielded a Lin's concordance correlation coefficient of 0.962 [95\% confidence interval $(\mathrm{CI})=0.951-0.971]$.

Response and survival analysis. The objective response rate (ORR) was assessed by RECIST. Overall survival (OS) was defined as the time from the first day of chemotherapy to death (all causes). Survivors were censored at last follow-up. Progression-free survival (PFS) was defined as the time from the first day of chemotherapy to the first recorded evidence of progression or death (all causes). Survivors without evidence of disease progression or those who underwent curative resection of metastatic sites were censored at last follow-up.

Analysis of study populations. The present analysis evaluated the association between treatment outcome (ORR, PFS, OS) and obesity-related factors [VFA, SFA, WST, and Body Mass Index (BMI)]. Patients were divided into two groups according to their percentiles of each obesity-related factor. This study was conducted adhering to the REporting recommendations for tumor MARKer prognostic studies (REMARK). Study protocols were approved by the institutional review boards of Kumamoto University (No. 653) and conducted in accordance with the Declaration of Helsinki and Ethical Guidelines for Clinical Studies.

Statistical analysis. Baseline patient and disease characteristics were summarized using descriptive statistics or contingency tables. The continuous values of the obesity-related factors were divided according to the median into two groups for each variable: VFA (high: $\geq 79.2 \mathrm{~cm}^{2}$, low: $<79.2 \mathrm{~cm}^{2}$ ), SFA (high: $\geq 97.7 \mathrm{~cm}^{2}$, low: $<97.7$ $\mathrm{cm}^{2}$ ), and WST (high: $\geq 80.1 \mathrm{~cm}$, low: $<80.1 \mathrm{~cm}$ ). Student's t-test and chi-square test or Fisher's exact test were used to compare means or proportions between groups, respectively. OS and PFS were compared between groups with a log-rank test; hazard ratio (HR) (with 95\% CI) were calculated with the Cox model. Survival curves were estimated using the Kaplan-Meier method. We constructed the multivariate Cox proportional hazards model to estimate the HR for the obesity-related factors (VFA, SFA, WST and BMI) adjusting for the potential baseline confounders; sex (male $v s$. female), age at treatment ( $<63 v s . \geq 63$ years, median), EOCG-PS (grade $0 v s .1 / 2$ ), tumor location (colon vs. rectum), and primary tumor (resected $v s$. unresected). We also carried out the multivariate logistic regression analysis to estimate the odds ratio for the ORR (responder/nonresponder) adjusting for the confounders described above. Test of interaction was conducted by including the cross product of the bevacizumab variable and another variable of interest in a univariate proportional hazard model. For all analyses, statistical significance was defined as a two-sided $p<0.05$. Statistical analyses were performed using R software ver.2.13.1 (http://cran.r-project.org/).

\section{Results}

The first-line KSCC trials used in the retrospective analysis of visceral fat are described in Figure 2. In total, 157 patients from five trials with available VFA, SFA, WST, BMI, PFS, and OS data were included in the analyses. The median OS was 33.0 months (95\% CI=25.5-36.6 months), and the median PFS was 10.9 months (95\% CI=9.6-12.9 months). Median length of follow-up among surviving patients was 29.6 months. 

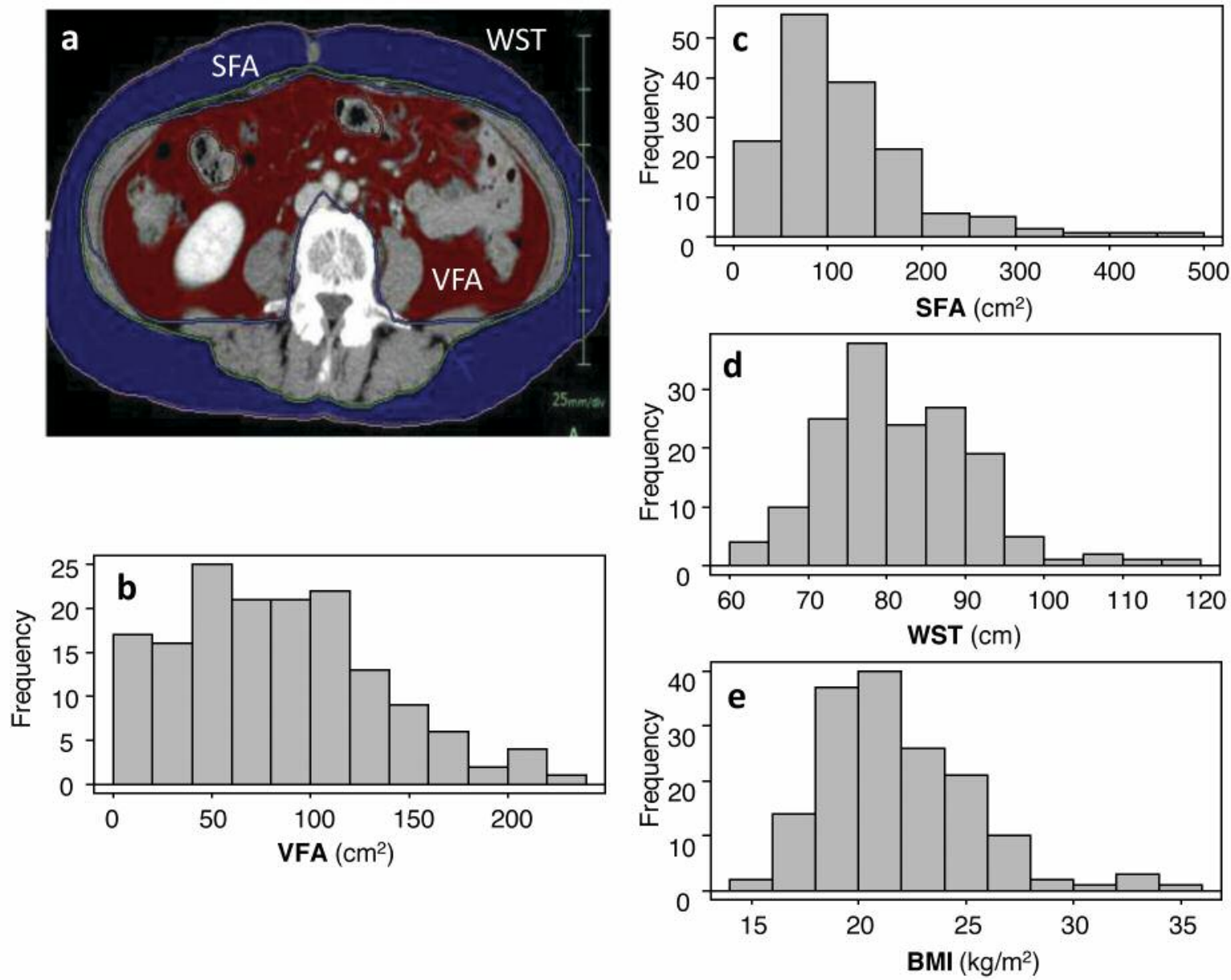

Figure 1. Measurement and distribution of obesity-related factors in colorectal cancer patients. a) Axial computed tomogram slice of the umbilicus level shows highlighted areas of visceral (red) fat and subcutaneous (blue) fat and waist circumference. b-e: Distribution of visceral fat area (VFA), subcutaneous fat area (SFA), waist circumference (WST) and body mass index (BMI) among 157 patients with metastatic colorectal cancer.

The baseline characteristics are shown in Table I. There was no statistically significant difference between the bevacizumab-treated group and the group treated with chemotherapy alone for the main characteristics except for chemotherapy regimens. In addition, there were no significant differences in the mean VFA, SFA, WST, and BMI between the two groups. The VFA in the 157 patients was distributed as follows (Figure 1b-e): mean= 88.0; median $=88.3$; standard deviation $(\mathrm{SD})=52.0$; range $=5.32$ 219.7 in male patients; and mean $=77.1$; median $=68.3$; $\mathrm{SD}=48.2$; range $=14.35-227.7$ in female patients.

In the group treated with chemotherapy alone, the ORR was $52.6 \%$ in the low VFA group and $63.2 \%$ in the high VFA group ( $p=0.47$ ). According to the log-rank test, there was no significant difference in PFS and OS between the low and high VFA groups (median $\mathrm{PF}=10.1$ vs. 9.4 months, $p=0.32$; median OS=25.1 vs. 33.6 months, $p=0.51$ ) (Figure 3).
In the bevacizumab group, the ORR was $44.6 \%$ in the low VFA group and $54.2 \%$ in the high VFA group $(p=0.30)$. According to log-rank test, the median PFS for patients in low and high VFA groups was 9.8 and 13.1 months, respectively. There was no significant difference in PFS between the two groups $(p=0.59)$. In contrast, patients in the low VFA group experienced significantly shorter OS (median $\mathrm{OS}=21.1$ vs. 38.9 months; $\mathrm{HR}=1.70,95 \% \mathrm{CI}=1.06-2.70$, $p=0.03$ ) than those in the high VFA group (Figure 3).

Cox multivariate modelling was performed to estimate whether VFA was independently associated with OS. Univariate analysis initially identified an association between low VFA and OS. Subsequent multivariate Cox analysis including age, gender, EOCG-PS, location of primary tumor, primary tumor resection, and VFA identified low VFA as an independent risk factor for $\mathrm{OS}(\mathrm{HR}=1.86$; 95\% $\mathrm{CI}=1.15$ $3.00, p=0.01$ ) (Table II). We further examined whether the 


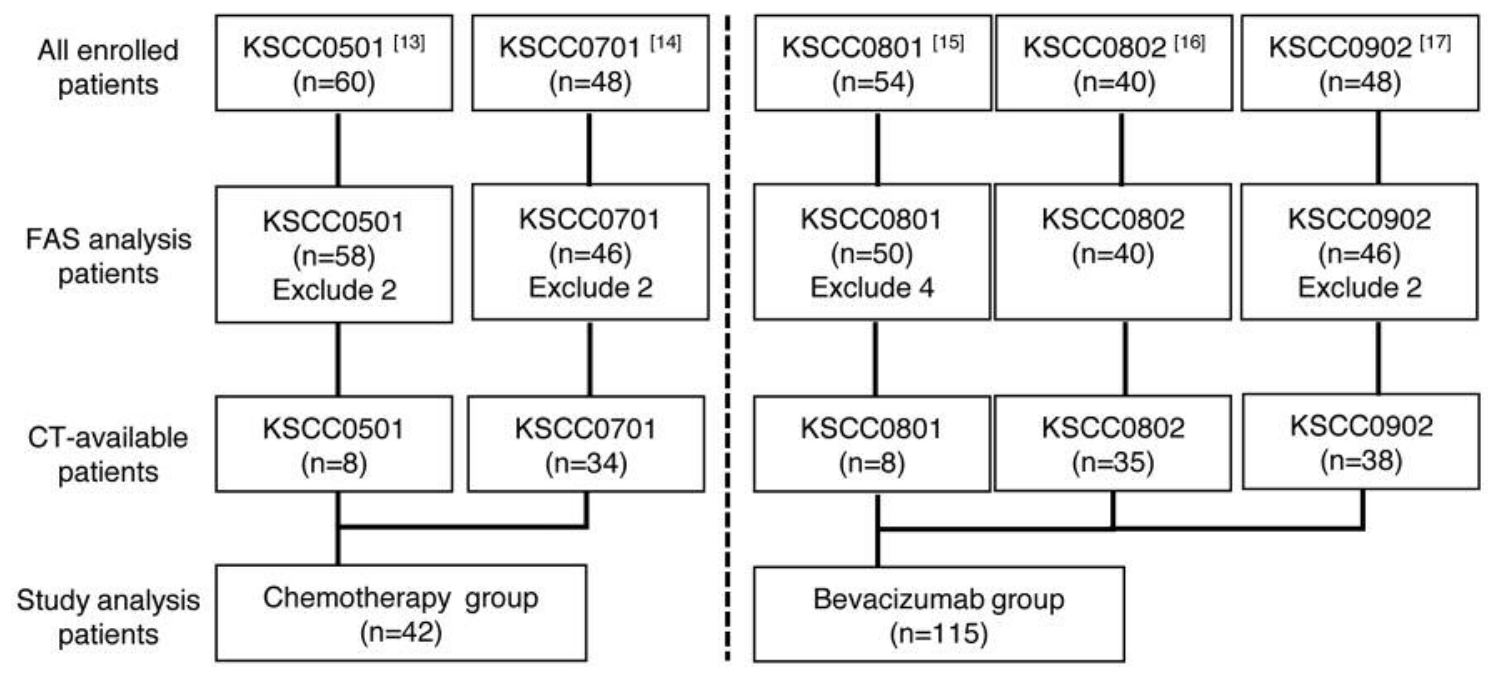

Figure 2. Study design. FAS: Full analysis set in each original study, CT: computed tomography.

association of OS and bevacizumab use was modified by clinical variables, and found a marginally significant modifying effect of VFA on the relationship between bevacizumab and OS ( $p$ for interaction=0.07) (Figure 4).

Finally, we evaluated the proportion of patients who received second- to fourth-line therapy among VFA groups (Table III). Second-line therapy was administered to $49(88 \%)$ out of 56 patients in the low VFA group and $53(90 \%)$ out of 59 patients in the high VFA group $(p>0.99)$, with a similar proportion of patients in each group treated with chemotherapy only [22/23 (96\%) vs. 18/19 (95\%), respectively, $p>0.99]$. The proportion of patients treated with second-line bevacizumab was also similar [27/56 (48\%) in the low VFA group and 27/59 (46\%) in the high VFA group, $p=0.86$. Similar results were also observed for third- and fourth-line treatment.

\section{Discussion}

In this study, we demonstrated that a low quantity of visceral fat plays a role as a negative predictive marker of OS of bevacizumab-based therapy in patients with mCRC. In the bevacizumab-treated group, OS was shorter in patients with low VFA than in patients with high VFA. In addition, VFA had a marginally significant modifying effect on the relationship between bevacizumab and OS. However, VFA was not significantly associated with OS in the group treated with chemotherapy alone. A summary of previous reports (Table IV) shows that patient adiposity as assessed by BMI or VFA was lower in our study population than that in other study populations. In addition, the prevalence of obesity (BMI $\geq 30 \mathrm{~kg} / \mathrm{m}^{2}$ ) in Japan is very much lower compared to that in Western countries (23). Therefore, we consider that the low VFA in this study indicates a very lean body type that includes cachexia status. To the best of our knowledge, this is the first study to report that very low visceral fat similar to cachexia status might inhibit the treatment efficacy of bevacizumab for mCRC.

Over the past decades, clinical research has focused on the study of molecular or clinical markers that can predict the activity of bevacizumab for individualized treatment of patients with mCRC. The expression level of VEGF and other angiogenic determinants (24), germline single-nucleotide polymorphisms of VEGF (25), bevacizumab-related arterial hypertension (26), and VEGF splice isoforms (27) have been investigated as potential biomarkers for anti-angiogenic treatment.

Renfro et al. showed that a low BMI to be associated with an increased risk of progression and death among patients enrolled in mCRC trials (28). They concluded that the negative effects were related to cancer cachexia in patients with a low BMI. In this study, worse OS for patients with low VFA compared with those with high VFA was observed only for patients in the bevacizumab-treated group. This suggests that some molecular signaling pathways associated with the cancer cachexia status may inhibit the effects of bevacizumab treatment. Possible explanations include increased expression of VEGF by tumor tissue in cachexia status (29-31); a high level of VEGF might induce inhibition of bevacizumab. In addition, activin, which is a member of the tumor growth factor superfamily, plays an important role in cancer cachexia as a multifactorial cytokine and may regulate angiogenic status in human cancer cells (32). Although VEGF expression is associated with advanced tumor progression and a poor prognosis in patients with colon cancer (33), no factors that 
Table I. Baseline characteristics of patients.

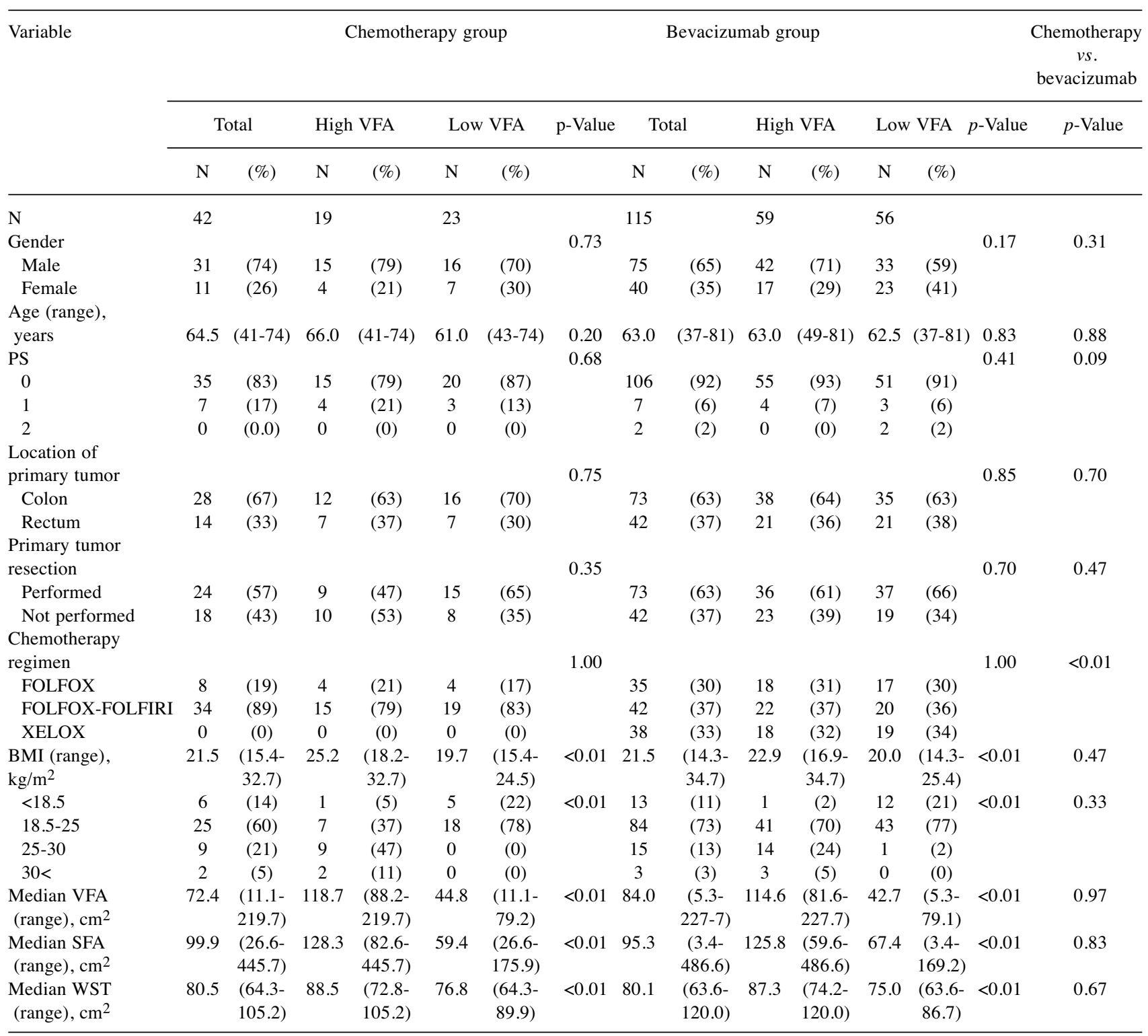

PS: Performance status, BMI: body mass index, VFA: visceral fat area, SFA: subcutaneous fat area, WST: waist circumference, SD: standard deviation.

predict the response to bevacizumab or conventional chemotherapy have been validated to date. Further studies in this field are therefore required.

Many investigators have reported that CT-based measurements of body composition, such as an increased amount of visceral fat, might be predictors of survival in patients with colon cancer $(34,35)$. However, the amount of visceral fat as a predictive marker for treatment effect has rarely been reported. Obtaining a pre-treatment image is important for assessing the effectiveness of chemotherapy, and the amount of visceral fat measured by pre-treatment CT, which is used as the main diagnostic tool, can be a useful predictive marker.

Some limitations should be addressed. Firstly, this was a retrospective study and, secondly, this study included a small number of patients, especially in the group treated with chemotherapy alone as control. In addition, this study showed no difference in PFS between high and low VFA groups. Nonetheless, our findings provide essential information about the correlation between bevacizumab and visceral fat using prospective clinical trial data. 
a

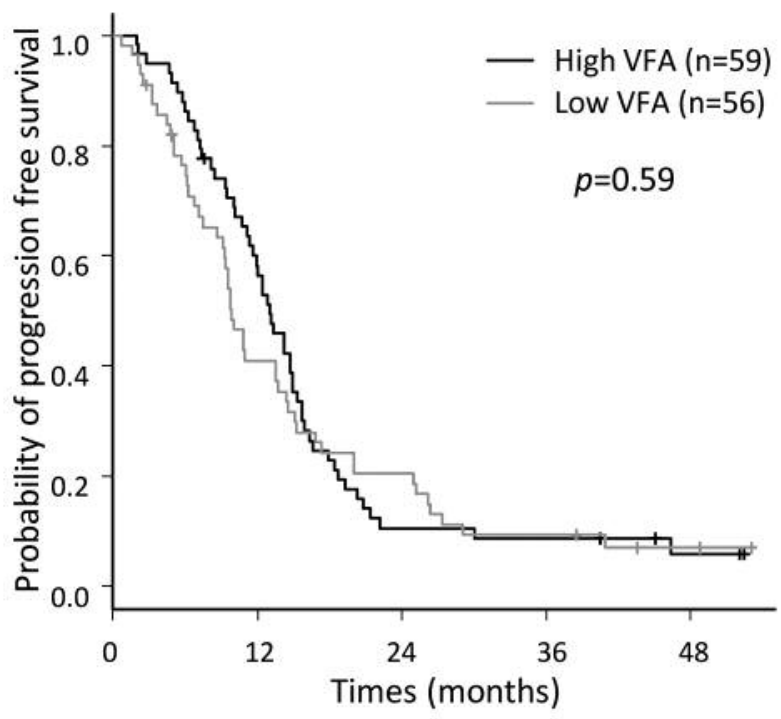

C

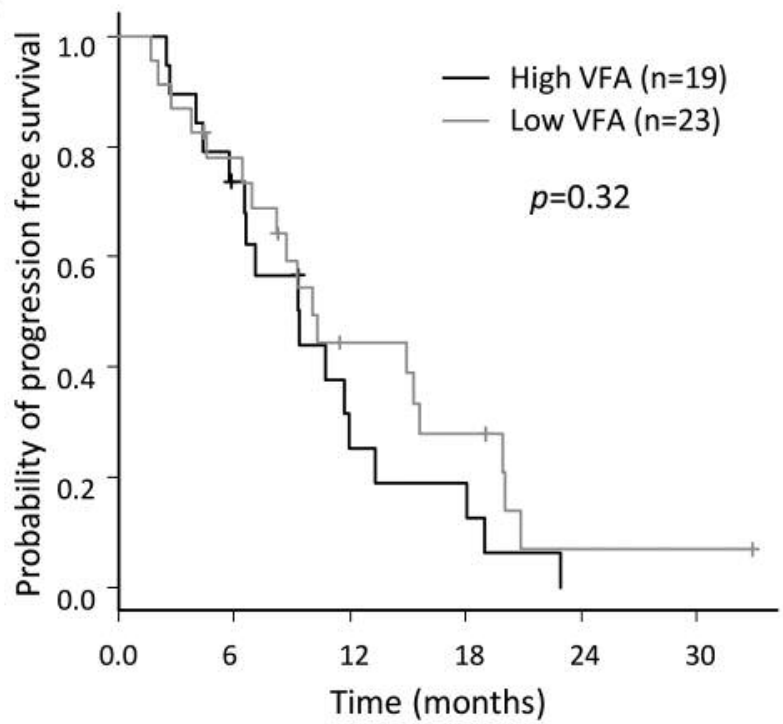

b

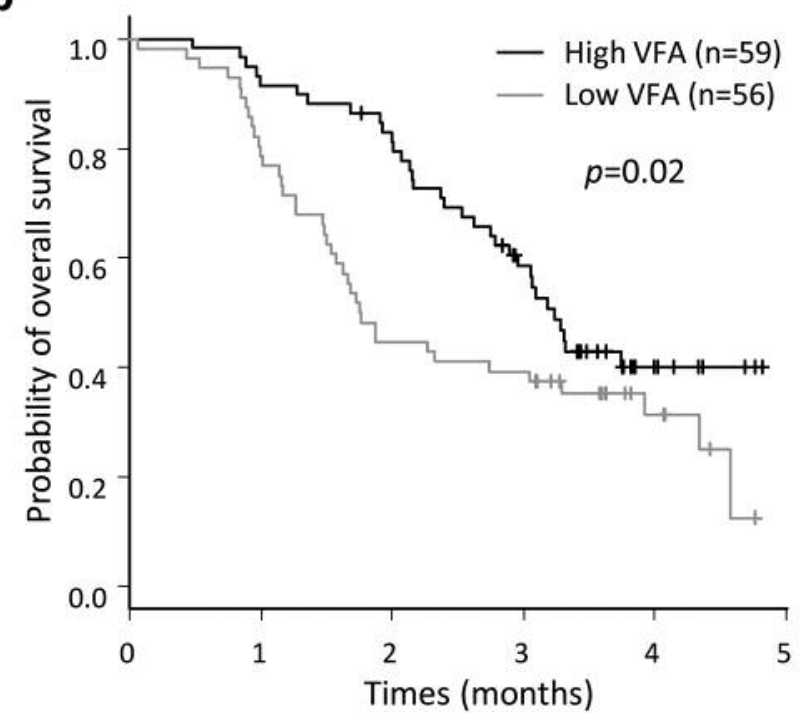

d

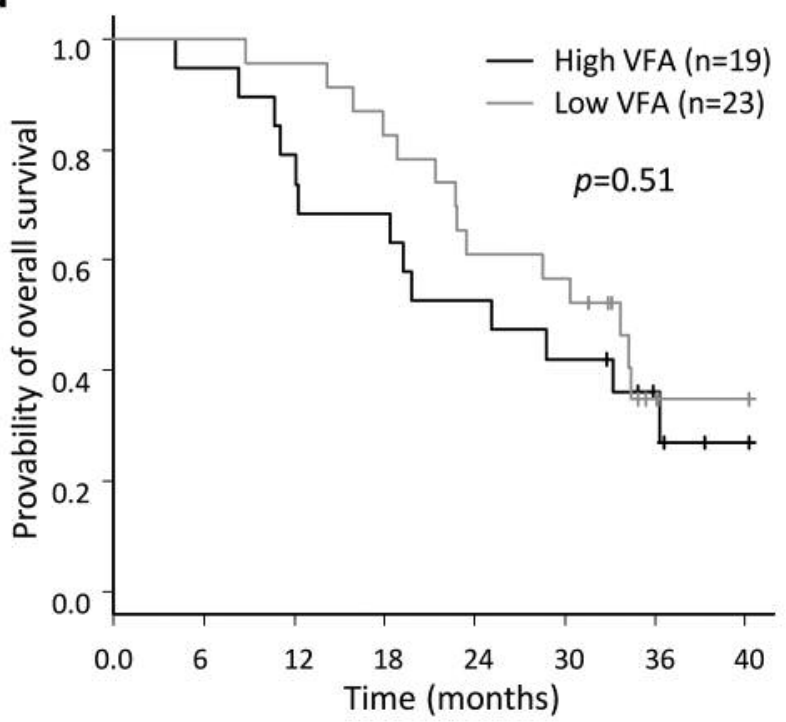

Figure 3. Kaplan-Meier analyses of progression-free survival $(a, c)$ and overall survival $(b, d)$ according to visceral fat area (VFA) in the group treated with chemotherapy plus bevacizumab $(a, b)$ and that treated with chemotherapy only $(a, c)$.

In conclusion, we demonstrated that a low amount of visceral fat might play a role as a negative predictive marker of bevacizumab-based therapy for patients with mCRC. Further studies are necessary to demonstrate clinical effectiveness and impact on the survival of patients with mCRC.

\section{Conflicts of Interest}

EO, YE, YA, YMa and HB received honorarium from Chugai Pharmaceutical Co. Ltd. EO, YA and HB received honorarium from Taiho Yakuhin Co. Ltd. EO and YMa received honorarium from Yakult Honsha Co. Ltd. EO and HB received honorarium from Merk Japan. EO and HB received honorarium from Bayer. EO and
YA received honorarium from Takeda Pharmaceutical Co. Ltd. YO, $\mathrm{HS}$, YMa and $\mathrm{HB}$ received research funding from Chugai Pharmaceutical Co. Ltd. YMa and HB received research funding from Yakult Honsha Co. Ltd. YMa and $\mathrm{Hb}$ received research funding from Taiho Yakuhin Co. Ltd. YMa received research funding from Merk. HB received research funding from Takeda Pharmaceutical Co. Ltd. YMi, ST, MS, YS and TT have no conflict of interest directly relevant to the content of this article.

\section{Acknowledgements}

The Authors thank the participating patients and their families very much. We are indebted to the physicians, all other co-medical staff (especially Ms. Yoshida at Kumamoto University) who contributed 
Table II. Multivariate analyses of survival outcome and objective response rate according to obesity-related factors and treatment.

\begin{tabular}{|c|c|c|c|c|}
\hline & \multicolumn{2}{|c|}{ Chemotherapy group } & \multicolumn{2}{|c|}{ Bevacizumab group } \\
\hline & Univariate HR (95\% CI) & Multivariate HR $(95 \% \mathrm{CI})^{*}$ & Univariate HR (95\% CI) & Multivariate HR $(95 \% \mathrm{CI}) *$ \\
\hline \multicolumn{5}{|l|}{ ORR } \\
\hline High VFA & 1 & 1 & 1 & 1 \\
\hline Low VFA & $0.64(0.18-2.20)$ & $0.78(0.18-3.23)$ & $0.68(0.33-1.42)$ & $0.68(0.32-1.45)$ \\
\hline$p$-Value & 0.48 & 0.73 & 0.30 & 0.32 \\
\hline \multicolumn{5}{|l|}{ PFS } \\
\hline High VFA & 1 & 1 & 1 & 1 \\
\hline Low VFA & $0.71(0.36-1.39)$ & $0.61(0.29-1.28)$ & $1.11(0.75-1.64)$ & $1.11(0.76-1.65)$ \\
\hline$p$-Value & 0.33 & 0.19 & 0.59 & 0.58 \\
\hline \multicolumn{5}{|l|}{ OS } \\
\hline High VFA & 1 & 1 & 1 & 1 \\
\hline Low VFA & $0.77(0.36-1.66)$ & $0.64(0.27-1.51)$ & $1.70(1.06-2.70)$ & $1.86(1.15-3.00)$ \\
\hline$p$-Value & 0.51 & 0.31 & 0.03 & 0.01 \\
\hline
\end{tabular}

OS: Overall survival, PFS: progression-free survival, ORR: objective response rate, HR: hazard ratio, CI: confidence interval, VFA: visceral fat area. *Multivariate analyses adjusted for age, sex, performance status, primary tumor location, prior primary tumor resection.

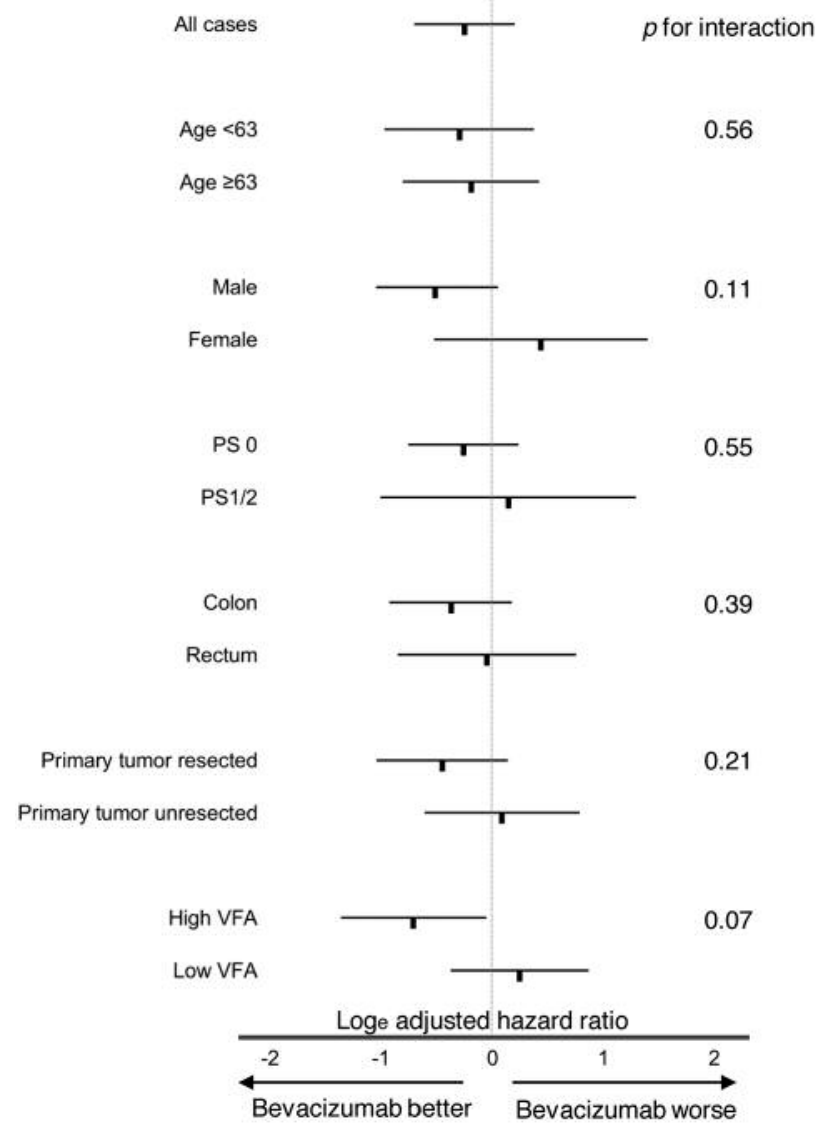

Figure 4. Subgroup analyses of overall survival according to bevacizumab treatment. The relation of bevacizumab on overall survival in various strata is shown by natural logarithms of adjusted hazard ratios with 95\% confidence interval. PS: Performance status, VFA: visceral fat area.
Table III. Frequency of second- to fourth-line treatment with chemotherapy with and without bevacizumab.

\begin{tabular}{|c|c|c|c|c|c|}
\hline \multirow[b]{2}{*}{ Chemotherapy } & \multicolumn{2}{|c|}{ Low VFA } & \multicolumn{2}{|c|}{ High VFA } & \multirow[t]{2}{*}{$p$-Value } \\
\hline & $\mathrm{N}$ & $(\%)$ & $\mathrm{N}$ & $(\%)$ & \\
\hline Chemotherapy + bevacizumab & \multicolumn{2}{|c|}{$(n=56)$} & \multicolumn{2}{|c|}{$(n=59)$} & \\
\hline 2nd-line & 49 & $(88)$ & 53 & $(90)$ & 1.00 \\
\hline With bevacizumab & 27 & (48) & 27 & (46) & 0.83 \\
\hline 3rd-line & 33 & (59) & 37 & (63) & 0.71 \\
\hline With bevacizumab & 11 & (20) & 12 & (20) & 0.63 \\
\hline 4th-line & 15 & (27) & 19 & (32) & 0.55 \\
\hline Chemotherapy only & \multicolumn{2}{|c|}{$(n=23)$} & \multicolumn{2}{|c|}{$(n=19)$} & \\
\hline 2nd-line & 22 & (96) & 18 & $(95)$ & 1.00 \\
\hline with bevacizumab & 8 & (35) & 4 & (21) & 0.32 \\
\hline 3rd-line & 16 & (70) & 11 & (58) & 0.52 \\
\hline with bevacizumab & 6 & (26) & 2 & (11) & 0.40 \\
\hline 4th-line & 10 & (43) & 7 & (37) & 0.76 \\
\hline
\end{tabular}

VFA: Visceral fat area.

to this study. We also thank Ms. Sakamoto, Mr. Shimose and the other staff at the Clinical Research Support Center Kyushu (CReS Kyushu) for their excellent collection and management of data, secretarial assistance, and any other supports.

\section{References}

1 Hurwitz H, Fehrenbacher L, Novotny W, Cartwright T, Hainsworth J, Heim W, Berlin J, Baron A, Griffing S, Holmgren E, Ferrara N, Fyfe G, Rogers B, Ross R and Kabbinavar F: Bevacizumab plus irinotecan, fluorouracil, and leucovorin for metastatic colorectal cancer. N Engl J Med 350: 2335-2342, 2004. 
Table IV. Summary of previous reports evaluated the association between bevacizumab efficacy and visceral fat /body mass index.

\begin{tabular}{|c|c|c|c|c|c|c|c|c|c|c|}
\hline Author & Year & $\begin{array}{l}\text { Cancer } \\
\text { type }\end{array}$ & $\begin{array}{l}\text { Evaluated } \\
\text { factor }\end{array}$ & $\mathrm{N}$ & $\begin{array}{c}\text { Mean } \\
\text { BMI } \\
\left(\mathrm{kg} / \mathrm{m}^{2}\right)\end{array}$ & $\begin{array}{c}\text { Patients ratio } \\
\text { BMI }>25 \\
\mathrm{~kg} / \mathrm{m}^{2}(\%)\end{array}$ & $\begin{array}{l}\text { Mean } \\
\text { VFA } \\
\left(\mathrm{cm}^{2}\right)\end{array}$ & $\begin{array}{l}\text { Mean } \\
\text { SFA } \\
\left(\mathrm{cm}^{2}\right)\end{array}$ & $\begin{array}{c}\text { Worse } \\
\text { PFS/TTP }\end{array}$ & $\begin{array}{c}\text { Worse } \\
\text { OS }\end{array}$ \\
\hline Simkens LH, et al. (36) & 2011 & $\mathrm{mCRC}$ & BMI & 1526 & - & 50 & - & - & - & ns \\
\hline Faruk AN, et al. (37) & 2013 & $\mathrm{mCRC}$ & BMI & 54 & - & 61 & - & - & BMI high & - \\
\hline Kaidar PO, et al. (38) & 2015 & $\mathrm{mCRC}$ & BMI & 184 & - & 63 & - & - & ns & ns \\
\hline Patel GS, et al. (39) & 2015 & $\mathrm{mCRC}$ & BMI & 1174 & - & 61 & - & - & ns & BMI high \\
\hline Guiu B, et al. (8) & 2010 & $\mathrm{mCRC}$ & VFA & 120 & 24.6 & - & 117.58 & 233.1 & VFA high & VFA high \\
\hline Ladoire S, et al. (9) & 2011 & $\mathrm{RCC}$ & VFA & 113 & 27.5 & - & 157.8 & 211.2 & VFA high & VFA high \\
\hline Steffens S, et al. (15) & 2011 & $\mathrm{RCC}$ & VFA & 116 & 26.5 & - & $141.4^{*}$ & 209.5 & VFA low & VFA low \\
\hline Slaughter N, et al. (10) & 2014 & OC & VFA & 46 & 28.6 & - & 75.1 & 276.1 & VFA high & ns \\
\hline Grignol VP, et al. (40) & 2015 & Melanoma & VFA & 42 & 27.0 & - & $187.6^{*}$ & 205.6 & VFA high & VFA high \\
\hline (Current study) & 2016 & mCRC & VFA & 157 & 21.9 & 18 & 84.7 & 114.5 & $\mathrm{~ns}$ & VFA low \\
\hline
\end{tabular}

mCRC: Metastatic colorectal cancer, RCC: renal cell carcinoma, OC: ovarian cancer, BMI: body mass index, VFA: visceral fat area, SFA: subcutaneous fat area, PFS: progression-free survival, TTP: time to progression, OS: overall survival, ns: no significance. *Median VFA.

2 Saltz LB, Clarke S, Díaz-Rubio E, Scheithauer W, Figer A, Wong R, Koski S, Lichinitser M, Yang T-SS, Rivera F, Couture F, Sirzén F, Cassidy J, Diaz-Rubio E, Scheithauer W, Figer A, Wong R, Koski S, Lichinitser M, Yang T-SS, Rivera F, Couture F, Sirzen F and Cassidy J: Bevacizumab incombination with oxaliplatin-based chemotherapy as first-line therapy in metastatic colorectal cancer: A randomized phase III study. J Clin Oncol 26: 2013-2019, 2008.

3 Hurwitz HI, Tebbutt NC, Kabbinavar F, Giantonio BJ, Guan ZZ, Mitchell L, Waterkamp D and Tabernero J: Efficacy and safety of bevacizumab in metastatic colorectal cancer: pooled analysis from seven randomized controlled trials. Oncologist 18 : 1004-1012, 2013

4 Kopetz S, Hoff PM, Morris JS, Wolff RA, Eng C, Glover KY, Adinin R, Overman MJ, Valero V, Wen S, Lieu C, Yan S, Tran HT, Ellis LM, Abbruzzese JL and Heymach J V.: Phase II trial of infusional fluorouracil, irinotecan, and bevacizumab for metastatic colorectal cancer: Efficacy and circulating angiogenic biomarkers associated with therapeutic resistance. J Clin Oncol 28: 453-459, 2010.

5 Ronzoni M, Manzoni M, Mariucci S, Loupakis F, Brugnatelli S, Bencardino K, Rovati B, Tinelli C, Falcone A, Villa E and Danova M: Circulating endothelial cells and endothelial progenitors as predictive markers of clinical response to bevacizumab-based first-line treatment in advanced colorectal cancer patients. Ann Oncol 21: 2382-2389, 2010.

6 Abajo A, Boni V, Lopez I, Gonzalez-Huarriz M, Bitarte N, Rodriguez J, Zarate R, Bandres E and Garcia-Foncillas J: Identification of predictive circulating biomarkers of bevacizumabcontaining regimen efficacy in pre-treated metastatic colorectal cancer patients. Br J Cancer 107: 287-290, 2012.

7 Bates DO, Catalano PJ, Symonds KE, Varey AHR, Ramani P, O'Dwyer PJ, Giantonio BJ, Meropol NJ, Benson AB and Harper $\mathrm{SJ}$ : Association between VEGF splice isoforms and progressionfree survival in metastatic colorectal cancer patients treated with bevacizumab. Clin Cancer Res 18: 6384-6391, 2012.

8 Guiu B, Petit JM, Bonnetain F, Ladoire S, Guiu S, Cercueil J-P, Krausé D, Hillon P, Borg C, Chauffert B and Ghiringhelli F: Visceral fat area is an independent predictive biomarker of outcome after first-line bevacizumab-based treatment in metastatic colorectal cancer. Gut 59: 341-347, 2010.

9 Ladoire S, Bonnetain F, Gauthier M, Zanetta S, Petit JM, Guiu S, Kermarrec I, Mourey E, Michel F, Krause D, Hillon P, Cormier L, Ghiringhelli F and Guiu B: Visceral fat area as a new independent predictive factor of survival in patients with metastatic renal cell carcinoma treated with antiangiogenic agents. Oncologist 16: 71-81, 2011.

10 Slaughter KN, Thai T, Penaroza S, Benbrook DM, Thavathiru E, Ding $\mathrm{K}$, Nelson $\mathrm{T}$, McMeekin DS and Moore $\mathrm{KN}$ : Measurements of adiposity as clinical biomarkers for first-line bevacizumab-based chemotherapy in epithelial ovarian cancer. Gynecol Oncol 133: 11-15, 2014.

11 Moon H-G, Ju Y-T, Jeong C-Y, Jung E-J, Lee Y-J, Hong S-C, Ha W-S, Park S-T and Choi S-K: Visceral obesity may affect oncologic outcome in patients with colorectal cancer. Ann Surg Oncol 15: 1918-1922, 2008.

12 Lemoine AY, Ledoux S, Quéguiner I, Caldérari S, Mechler C, Msika S, Corvol P and Larger E: Link between adipose tissue angiogenesis and fat accumulation in severely obese subjects. $\mathbf{J}$ Clin Endocrinol Metab 97: 775-780, 2012.

13 Miyazawa-Hoshimoto S, Takahashi K, Bujo H, Hashimoto N and Saito Y: Elevated serum vascular endothelial growth factor is associated with visceral fat accumulation in human obese subjects. Diabetologia 46: 1483-1488, 2003.

14 Doyle SL, Bennett AM, Donohoe CL, Mongan AM, Howard JM, Lithander FE, Pidgeon GP, Reynolds JV and Lysaght J: Establishing computed tomography-defined visceral fat area thresholds for use in obesity-related cancer research. Nutr Res 33: 171-179, 2013.

15 Steffens S, Grunwald V, Ringe KI, Seidel C, Eggers H, Schrader M, Wacker F, Kuczyk MA and Schrader AJ: Does obesity influence the prognosis of metastatic renal cell carcinoma in patients treated with vascular endothelial growth factor-targeted therapy? Oncologist 16: 1565-1571, 2011.

16 Miyamoto Y, Hanna DL, Zhang W, Baba H and Lenz H-J: Molecular Pathways: Cachexia Signaling-A Targeted Approach to Cancer Treatment. Clin Cancer Res 22: 3999-4004, 2016.

17 Kusumoto T, Emi Y, Kakeji Y, Akagi Y, Samura H, Baba H, Natsugoe S, Tokunaga S and Maehara Y: Analysis of oxaliplatin- 
induced sensory neurotoxicity (sNT) in patients receiving FIREFOX, alternating regimen of mFOLFOX-6 and FOLFIRI, with metastatic colorectal cancer (mCRC): Results from combined analysis of KSCC0501 and KSCC0701. J Clin Oncol 29: 492, 2011.

18 Oki E, Emi Y, Akagi Y, Tokunaga S, Sadanaga N, Tanaka T, Ogata Y, Saeki H, Kakeji Y, Baba H, Nishimaki T, Natsugoe S, Shirouzu K and Maehara Y: Phase II trial of alternating mFOLFOX6 and FOLFIRI regimens in the first-line treatment for unresectable or metastatic colorectal cancer (KSCC0701). Oncology 84: 233-239, 2013.

19 Miwa K, Oki E, Emi Y, Saeki H, Kusumoto T, Akagi Y, Ogata Y, Samura H, Tokunaga S, Ishikawa H, Tanaka T, Sueyoshi S, Higashi H, Matsuda H, Touyama T and Maehara Y: Phase II trial of an alternating regimen consisting of first-line mFOLFOX6 plus bevacizumab and FOLFIRI plus bevacizumab for patients with metastatic colorectal cancer: FIREFOX plus bevacizumab trial (KSCC0801). Int J Clin Oncol 21: 110-117, 2016.

20 Beppu T, Emi Y, Tokunaga S, Oki E, Shirabe K, Ueno S, Kuramoto M, Kabashima A, Takahashi I, Samura H, Eguchi S, Akagi Y, Natsugoe S, Ogata Y, Kakeji Y, Baba H and Maehara Y: Liver resectability of advanced liver-limited colorectal liver metastases following mFOLFOX6 with bevacizumab (KSCC0802 Study). Anticancer Res 34: 6655-6662, 2014.

21 Ogata Y, Shimokawa M, Tanaka T, Emi Y, Oki E, Saeki H, Sadanaga N, Kusumoto T, Touyama T, Kimura M, Baba H, Akagi Y, Shirouzu K and Maehara Y: A prospective study of XELOX plus bevacizumab as first-line therapy in Japanese patients with metastatic colorectal cancer (KSCC 0902). Int J Clin Oncol 21: 335-343, 2016.

22 Eisenhauer EA, Therasse P, Bogaerts J, Schwartz LH, Sargent D, Ford R, Dancey J, Arbuck S, Gwyther S, Mooney M, Rubinstein L, Shankar L, Dodd L, Kaplan R, Lacombe D and Verweij J: New response evaluation criteria in solid tumours: Revised RECIST guideline (version 1.1). Eur J Cancer 45: 228247, 2009.

23 Kanazawa M, Yoshiike N, Osaka T, Numba Y, Zimmet P and Inoue S: Criteria and classification of obesity in Japan and AsiaOceania. World Rev Nutr Diet 11: S732-S737, 2005.

24 Jubb AM, Hurwitz HI, Bai W, Holmgren EB, Tobin P, Guerrero AS, Kabbinavar F, Holden SN, Novotny WF, Frantz GD, Hillan $\mathrm{KJ}$ and Koeppen $\mathrm{H}$ : Impact of vascular endothelial growth factor-A expression, thrombospondin-2 expression, and microvessel density on the treatment effect of bevacizumab in metastatic colorectal cancer. J Clin Oncol 24: 217-227, 2006.

25 Schneider BP, Shen F and Miller KD: Pharmacogenetic biomarkers for the prediction of response to antiangiogenic treatment. Lancet Oncol 13: e427-e436, 2012.

26 Scartozzi M, Galizia E, Chiorrini S, Giampieri R, Berardi R, Pierantoni $\mathrm{C}$ and Cascinu S: Arterial hypertension correlates with clinical outcome in colorectal cancer patients treated with first-line bevacizumab. Ann Oncol 20: 227-230, 2009.

27 Bates DO, Catalano PJ, Symonds KE, Varey AHR, Ramani P, O'Dwyer PJ, Giantonio BJ, Meropol NJ, Benson AB and Harper SJ: Association between VEGF splice isoforms and progressionfree survival in metastatic colorectal cancer patients treated with bevacizumab. Clin Cancer Res 18: 6384-6391, 2012

28 Renfro L a, Loupakis F, Adams R a, Seymour MT, Schmoll HJ, Douillard J-Y, Hurwitz H, Fuchs CS, Diaz-Rubio E, Porschen R, Tournigand C, Chibaudel B, Falcone A, Tebbutt NC, Punt CJ a, Hecht JR, Bokemeyer C, Van Cutsem E, Goldberg RM, Saltz LB, de Gramont A, Sargent DJ and Lenz H-J: Body mass index is prognostic in metastatic colorectal cancer: pooled analysis of patients from first-line clinical trials in the ARCAD Database. J Clin Oncol 34: 144-150, 2016.

29 Watanabe T, Shibata M, Nishiyama H, Soeda S, Furukawa S, Gonda K, Takenoshita S and Fujimori K: Elevated serum levels of vascular endothelial growth factor is effective as a marker for malnutrition and inflammation in patients with ovarian cancer. Biomed reports 1: 197-201, 2013.

30 Ding G, Feng C, Song N, Fang Z, Xia G, Jiang H, Hua L and Ding Q: Paraneoplastic symptoms: cachexia, polycythemia, and hypercalcemia are, respectively, related to vascular endothelial growth factor (VEGF) expression in renal clear cell carcinoma. Urol Oncol 31: 1820-1825, 2013.

$31 \mathrm{Xu}$ X, Jiang M, Zhang Y, Bi Y and Han M: Celecoxib attenuates cachectic events in mice by modulating the expression of vascular endothelial growth factor. Mol Med Rep 11: 289-294, 2015.

32 Wagner K, Peters M, Scholz A, Benckert C, Ruderisch HS, Wiedenmann B and Rosewicz S: Activin A stimulates vascular endothelial growth factor gene transcription in human hepatocellular carcinoma cells. Gastroenterology 126: 1828-1843, 2004.

33 Hicklin DJ and Ellis LM: Role of the vascular endothelial growth factor pathway in tumor growth and angiogenesis. J Clin Oncol 23: 1011-1027, 2005.

34 Frezza EE, Wachtel MS and Chiriva-Internati M: Influence of obesity on the risk of developing colon cancer. Gut 55: 285-291, 2006.

35 Rickles AS, Iannuzzi JC, Mironov O, Deeb AP, Sharma A, Fleming FJ and Monson JRT: Visceral Obesity and Colorectal Cancer: Are We Missing the Boat with BMI? J Gastrointest Surg 17: 133-143, 2013.

36 Simkens LHJ, Koopman M, Mol L, Veldhuis GJ, Ten Bokkel Huinink D, Muller EW, Derleyn VA, Teerenstra S and Punt CJA: Influence of body mass index on outcome in advanced colorectal cancer patients receiving chemotherapy with or without targeted therapy. Eur J Cancer 47: 2560-2567, 2011.

37 Faruk Aykan N, Yildiz I, Sen F, Kilic L, Keskin S, Ciftci R, Karabulut S, Sakar B and Disci R: Effect of increased body mass index (BMI) on time to tumour progression (TTP) in unresectable metastatic colorectal cancer (mCRC) patients treated with bevacizumab-based therapy. Med Oncol 30: 679, 2013.

38 Kaidar-Person O, Badarna H and Bar-Sela G: Bevacizumab for metastatic colon cancer: does patient BMI influence survival? Anticancer Drugs 26: 363-366, 2015.

39 Patel GS, Ullah S, Beeke C, Hakendorf P, Padbury R, Price TJ and Karapetis CS: Association of BMI with overall survival in patients with $\mathrm{mCRC}$ who received chemotherapy versus EGFR and VEGF-targeted therapies. Cancer Med 4: 1461-1471, 2015.

40 Grignol VP, Smith AD, Shlapak D, Zhang X, Del Campo SM and Carson WE: Increased visceral to subcutaneous fat ratio is associated with decreased overall survival in patients with metastatic melanoma receiving anti-angiogenic therapy. Surg Oncol 24: 353-358, 2015 